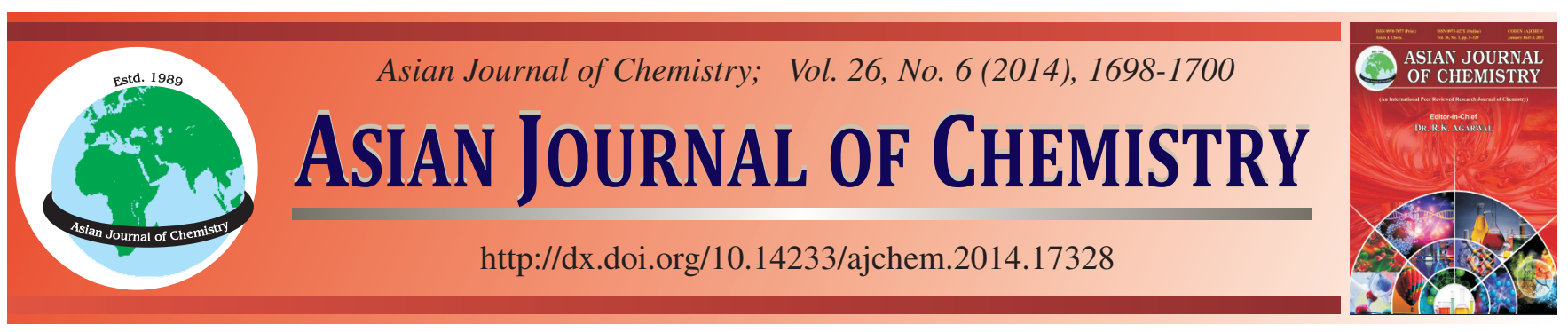

\title{
Structure and Electrical Properties of Lead-free Piezoelectric Ceramics $\mathrm{Bi}_{0.5} \mathrm{Na}_{0.5} \mathrm{TiO}_{3}-\mathrm{Ba}_{0.94} \mathrm{Sr}_{0.06}\left(\mathrm{Sn}_{0.08} \mathrm{Ti}_{0.92}\right) \mathrm{O}_{3} \dagger$
}

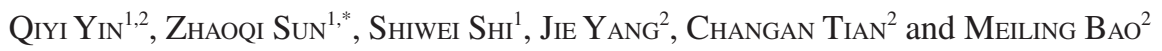

${ }^{1}$ School of Physics and Material Science, Anhui University, Hefei 230601, P.R. China

${ }^{2}$ Department of Chemistry and Material Engineering, Hefei University, Hefei 230601, P.R. China

*Corresponding author: E-mail: szq@ ahu.edu.cn

New lead-free piezoelectric ceramics BNBSST-100x have been prepared by the traditional solid state sintering technique and systematically studied. The results of XRD confirm that all ceramics samples possess pure perovskite structure, showing that the morphotropic phase boundary between rhombohedral and tetragonal phase of the ceramics locates in the range of $0.02<\mathrm{x}<0.06$. The BNBSST- 4 ceramic samples near the morphotropic phase boundary exhibits improved properties, which are $\mathrm{d}_{33}=203 \mathrm{pC} / \mathrm{N}, \mathrm{k}_{\mathrm{p}}=41 \%, \varepsilon_{\mathrm{r}}=1128, \tan \theta=2.6 \%$, $\mathrm{P}_{\mathrm{r}}=35.6 \mu \mathrm{C} / \mathrm{cm}^{2}$ and $\mathrm{E}_{\mathrm{C}}=3.51 \mathrm{kV} / \mathrm{mm}$, suggesting that the ceramics are suitable for future application.

Keywords: Lead-free, Piezoelectric ceramics, $\mathrm{SnO}_{2}$, Ferroelectricity.

\section{INTRODUCTION}

All kinds of piezoelectric ceramics have been extensively studied and widely used in different related devices due to discovery of piezoelectric effect in 1880 by J. and P. Curie ${ }^{1}$. Particularly, lead-based piezoelectric ceramics based on lead zirconate titanate (PZT) are universally used for various actuator, sensor applications as well as microelectronic devices result from their excellent piezoelectric properties. In recent years, the search for alternative piezoelectric materials is a very active research topic and a great deal of attention has been focused on different types of lead-free piezoelectric ceramics, which because the use of the lead-based ceramics can cause serious lead pollution to man and environmental due to the high toxicity of lead oxide and a high volatility even at low temperatures ${ }^{2,3}$. Thus, it is urgent to develop environmentfriendly materials which can replace lead zirconate titanatebased ceramics. Bismuth sodium titanate (BNT) discovered by Smolenskii and Aganovskaya ${ }^{4}$ is one of the most important lead-free piezoelectric materials because of its excellent piezoelectric and ferroelectric properties as well as the lack of lead pollution during the preparation process ${ }^{4}$. However, the electrical properties of pure bismuth sodium titanate is quite poor due to its relatively high conductivity and large coercive field. As a result of these, a lot of important work is focused on the modification and preparation technology of the bismuth sodium titanate-based ceramics so that their electrical properties are improved ${ }^{5,6}$.

In this work, lead-free piezoelectric ceramics (1-x) $\mathrm{Bi}_{0.5} \mathrm{Na}_{0.5} \mathrm{TiO}_{3}-\mathrm{xBa}_{0.94} \mathrm{Sr}_{0.06}\left(\mathrm{Sn}_{0.08} \mathrm{Ti}_{0.92}\right) \mathrm{O}_{3}$ (BNBSST) were synthesized by the traditional solid-state reaction processes at $1140{ }^{\circ} \mathrm{C}$. Their phase composition, microstructure, electrical properties were also investigated.

\section{EXPERIMENTAL}

The piezoelectric ceramics $(1-\mathrm{x}) \mathrm{Bi}_{0.5} \mathrm{Na}_{0.5} \mathrm{TiO}_{3}$ $\mathrm{xBa}_{0.94} \mathrm{Sr}_{0.06}\left(\mathrm{Sn}_{0.08} \mathrm{Ti}_{0.92}\right) \mathrm{O}_{3}(\mathrm{x}=0.00,0.02,0.04,0.06,0.08)$ (abbreviated as BNBSST-100x) were prepared by a conventional ceramic process using high purity oxides or carbonate powders of $\mathrm{Bi}_{2} \mathrm{O}_{3}(99.97 \%), \mathrm{TiO}_{2}(99.9 \%), \mathrm{SnO}_{2}(99.98 \%)$, $\mathrm{Na}_{2} \mathrm{CO}_{3}(99.9 \%), \mathrm{BaCO}_{3}(99.9 \%)$ and $\mathrm{SrCO}_{3}(99.9 \%)$ as starting raw materials. Firstly, these powders were weighed and mixed fully in the appropriate stoichiometry in ethanol by ball-milling which medium is agate ball for $24 \mathrm{~h}$ and calcined at $900^{\circ} \mathrm{C}$ for $2 \mathrm{~h}$. After calcining, the calcined powders were milled again for $10 \mathrm{~h}$ and mixed thoroughly with a PVA binder solution and then pressed uniaxially into disk samples of $1.2 \mathrm{~cm}$ in diameter and $1.0 \mathrm{~mm}$ in thickness. These disk samples were sintered at $1140{ }^{\circ} \mathrm{C}$ for $2 \mathrm{~h}$ in atmospheric air. Silver electrodes were fired on both sides of the samples at

†Presented at The 7th International Conference on Multi-functional Materials and Applications, held on 22-24 November 2013, Anhui University of Science \& Technology, Huainan, Anhui Province, P.R. China 

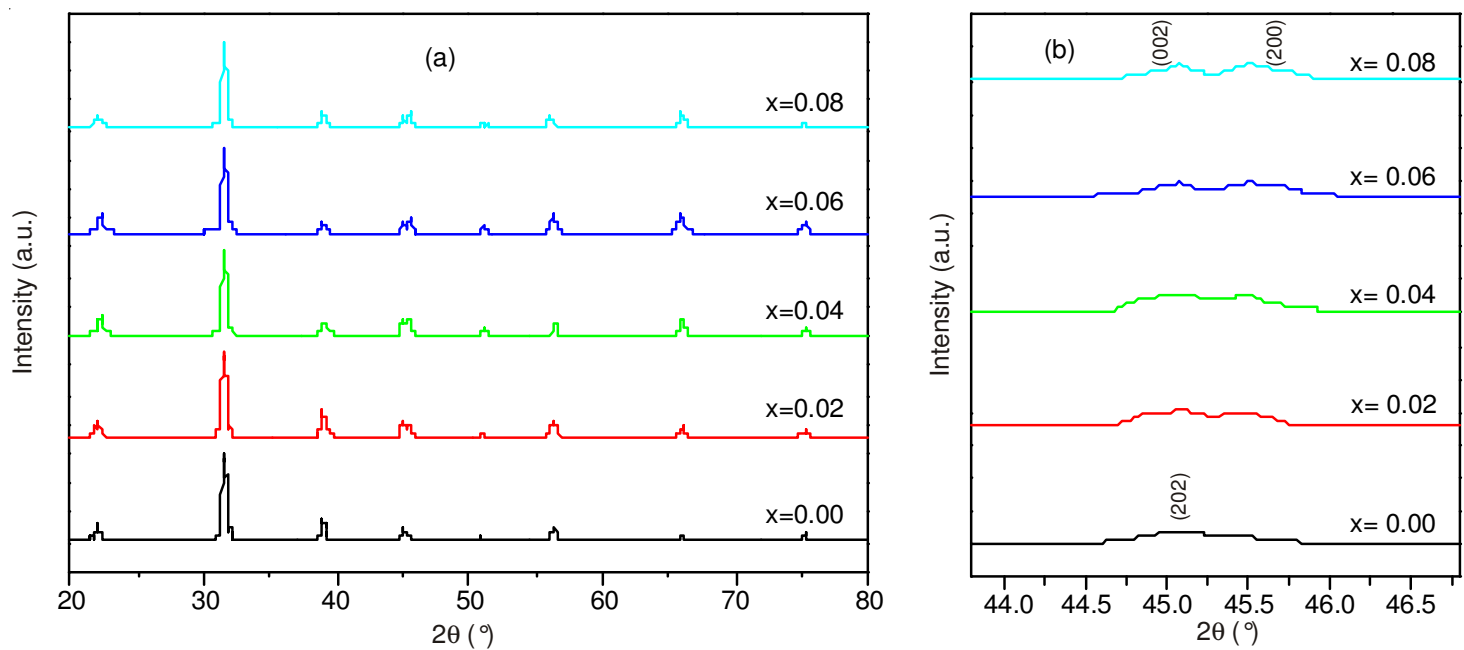

Fig. 1. (a) and (b) XRD patterns of the BNBSST-100x piezoelectric ceramics

$500{ }^{\circ} \mathrm{C}$ for $0.5 \mathrm{~h}$ in order to the subsequent poling and electrical measurements. The samples were poled in $70{ }^{\circ} \mathrm{C}$ silicon oil bath using a DC electric field of $3-5 \mathrm{kV} / \mathrm{mm}$ for $0.5 \mathrm{~h}$. The crystalline structure of the sintered samples was examined using an X-ray diffraction (XRD) with $\mathrm{CuK}_{\alpha}$ radiation (Rigaku, Tokyo, Japan). The microstructure of the ceramics was studied by scanning electron microscope (SEM) (S-4800, Hitachi, Japan). The piezoelectric constant $\mathrm{d}_{33}$ was measured using a piezo- $\mathrm{d}_{33}$ meter (ZJ-3A, China). The electromechanical coupling factor $\mathrm{k}_{\mathrm{p}}$ was determined by the resonance method using an impedance analyzer (Agilent 4294A). The relative permittivity $\varepsilon_{\mathrm{r}}$ and loss tangent $\tan \delta$ of the ceramics at $10 \mathrm{kHz}$ were measured using an impedance analyzer (Agilent 4192A). Ferroelectric hysteresis loops were measured at room temperature using a ferroelectric tester (Trek 609B, Radiant Technologies, Inc., Albuquerque, NM)

\section{RESULTS AND DISCUSSION}

The XRD patterns of the BNBSST-100x ceramics sintered at $1140{ }^{\circ} \mathrm{C}$ are shown in Fig. 1. As shown in Fig. 1(a), all the ceramics possess a pure perovskite structure and no second phases are detected, indicating that $\mathrm{Ba}^{2+}, \mathrm{Sr}^{2+}, \mathrm{Sn}^{4+}$ and $\mathrm{Ti}^{4+}$ have completely diffused into the bismuth sodium titanate lattices to form a series of continuous solid solutions. Similar to pure bismuth sodium titanate ceramics, it is obvious that only the (202) characteristic peaks are shown when $\mathrm{x} \leq 0.02$, implying that the BNBSST-100x ceramics have a rhombohedral perovskite structure. However, with $\mathrm{x}$ increasing from 0.02 to 0.06 , the crystal structure of the BNBSST-100x ceramics transforms featured with the splitting of (202) diffraction peak into (002) and (200) peaks at $44-47^{\circ} \mathrm{C}$ and the intensities of the two peaks change with the increasing of tetragonal phase and at $x \geq 0.06$, the ceramics exhibit the single tetragonal phase, which are presented in Fig. 1(b). These results reveals that the morphotropic phase boundary (MPB) between rhombohedral and tetragonal structures is formed in the BNBSST-100x ceramics with $0.02<x<0.06$. Similar results have been obtained in the other bismuth sodium titanate-based ceramics reported ${ }^{7}$.

Fig. 2 shows the SEM micrographs of the BNBSST-4 ceramics sintered at $1140^{\circ} \mathrm{C}$ for $2 \mathrm{~h}$. As can be seen from Fig. 2(a), almost no pores are found on the surface and grains boundary is very clear. Fig. 2(b) exhibits the SEM micrographs of a transect of the BNBSST-4 ceramics, there are a few small pores and a stain which might be caused during the preparation in the body of the ceramics, the fracture behaviour of the ceramics is penetrating grain fracture, indicating the existence of good mechanics properties. From the both pictures of Fig. 2, the observations of SEM micrographs affirm that this ceramic is densely sintered and $1140{ }^{\circ} \mathrm{C}$ is an appropriate sintering temperature.

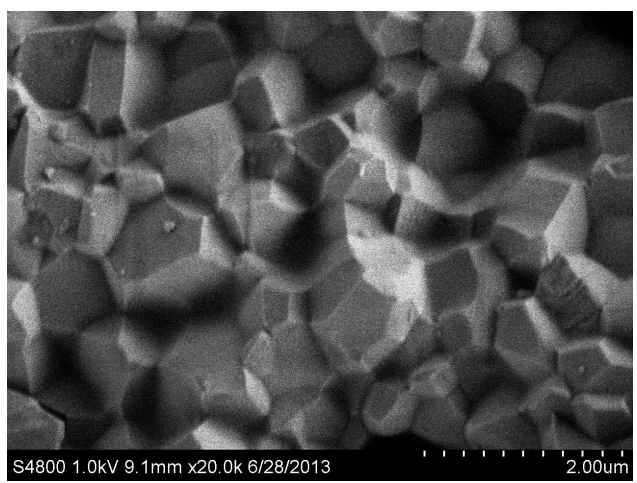

(b)

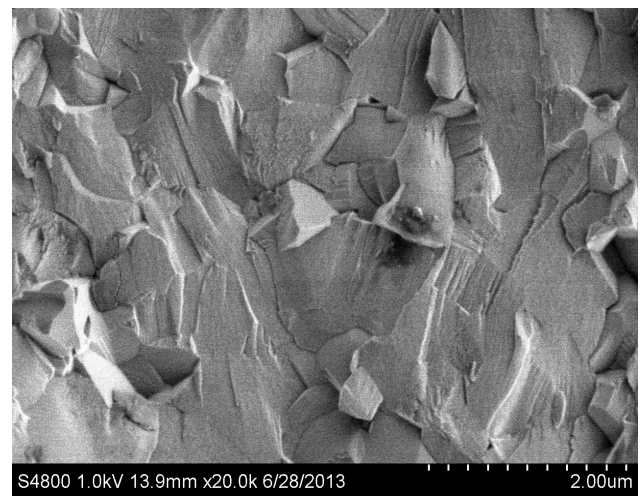

(a)

Fig. 2. SEM micrographs of the BNBSST-100x $(x=0.04)$ ceramic at 1140 ${ }^{\circ} \mathrm{C}$ for 2 h. (a) External; (b) transect

The piezoelectric and dielectric properties $\left(\mathrm{d}_{33}, \mathrm{k}_{\mathrm{p}}, \varepsilon_{\mathrm{r}}\right.$ and $\tan \delta$ ) of the BNBSST-100x ceramics as a function of $\mathrm{Ba}_{0.94} \mathrm{Sr}_{0.06}\left(\mathrm{Sn}_{0.08} \mathrm{Ti}_{0.92}\right) \mathrm{O}_{3}(\mathrm{BSST})$ concentration were measured 
are shown in Fig. 3. As can be seen from Fig. 3(a), the piezoelectric constant $d_{33}$ and the planar electromechanical coupling factor $\mathrm{k}_{\mathrm{p}}$ of BNBSST-100x ceramics increase with increasing BSST fraction up to 0.04 and then decrease with further increase in $\mathrm{x}$ value in BNBSST-100x ceramics. The maximum values of $\mathrm{d}_{33}=203 \mathrm{pC} / \mathrm{N}$ and $\mathrm{k}_{\mathrm{p}}=41 \%$ are obtained at $\mathrm{x}=$ 0.04. As for Fig. 3(b), it can been observed that the variation tendency of $\varepsilon_{\mathrm{r}}$ with increasing BSST content is similar to the change law of piezoelectric properties and $\varepsilon_{\mathrm{r}}$ reachs the maximum value of 1128 at $x=0.04$, but $\tan \delta$ change is just opposite comparing with $\varepsilon_{\mathrm{r}}$ and reaches a minimum value of $2.6 \%$ at $\mathrm{x}$ $=0.04$. The results indicate that an optimal piezoelectric and dielectric properties can be gained at the composition $\mathrm{x}=0.04$ near the morphotropic phase boundary.
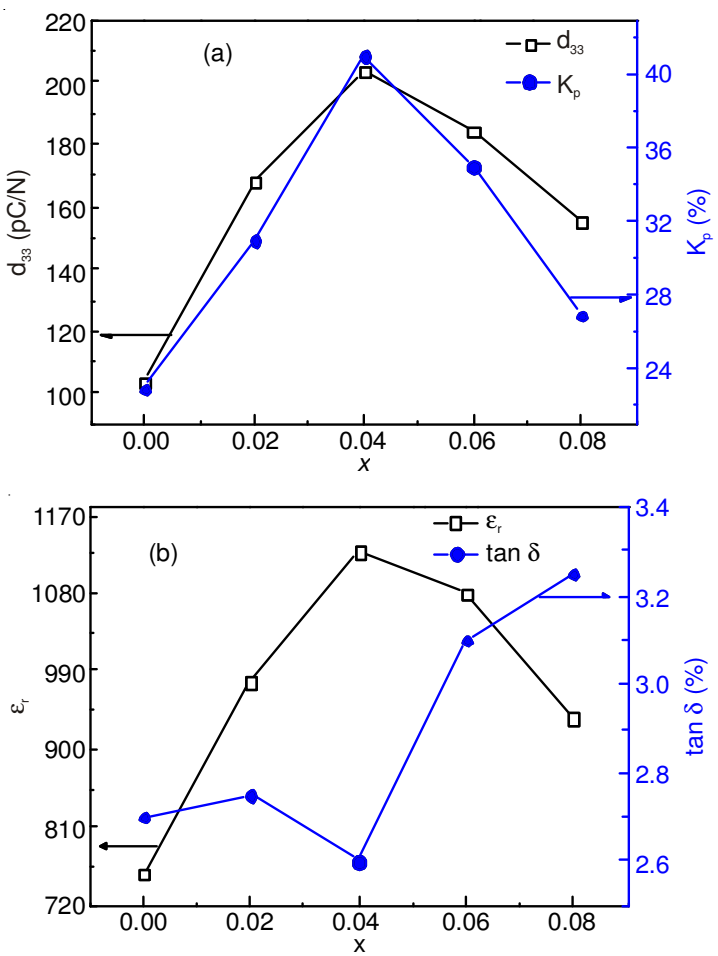

Fig. 3. Variations of (a) Piezoelectric and (b) dielectric properties (at 10 $\mathrm{kHz}$ ) with $\mathrm{x}$ for the BNBSST-100x ceramics

Fig. 4(a) shows the P-E curves of the BNBSST-100x ( $\mathrm{x}=$ $0.00,0.02,0.04,0.06,0.08$ ) ceramics at room temperature. All these ceramics samples exhibit a typical P-E loops of ferroelectrics with square like shape, a relatively steep P-E slope, especially the BNBSST-100x $(\mathrm{x}=0.04,0.06)$ ceramics exhibit strong ferroelectric properties. Fig. 4(b) presents the remnant polarization $\mathrm{P}_{\mathrm{r}}$ and coercive field $\mathrm{E}_{\mathrm{C}}$ as a function of $\mathrm{x}$. It is exhibited that $\mathrm{P}_{\mathrm{r}}$ and $\mathrm{E}_{\mathrm{C}}$ of the BNBSST-100x ceramics increases with $\mathrm{x}$ increasing, reaching a maximum value of $35.6 \mu \mathrm{C} / \mathrm{cm}^{2}$ and $3.51 \mathrm{kV} / \mathrm{mm}$ at $\mathrm{x}=0.04$, then $\mathrm{P}_{\mathrm{r}}$ and $\mathrm{E}_{\mathrm{C}}$ decreases when $\mathrm{x}$ further increasing, which indicating that the strongest ferroelectricity of BNBSST-4 ceramic in all the samples is inseparable from excellent piezoelectric properties at $\mathrm{x}=0.04$.

\section{Conclusion}

New lead-free piezoelectric ceramics BNBSST-100x have been prepared by the conventional solid state sintering method. The crystal structures, microstructure, dielectric, piezoelectric
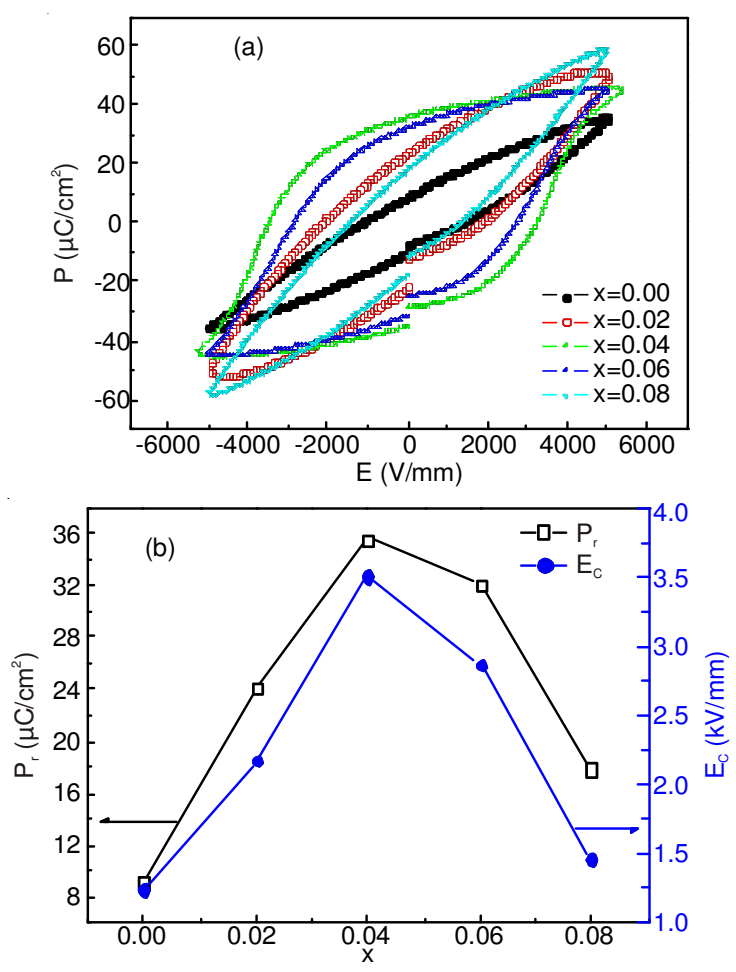

Fig. 4. (a) P-E curves and (b) $\mathrm{P}_{\mathrm{r}}, \mathrm{E}_{\mathrm{C}}$ as a function of $\mathrm{x}$ for the BNBSST$100 \mathrm{x}$ ceramics at room temperature

and ferroelectric properties of the ceramics have been studied. $\mathrm{X}$-ray diffraction confirms that a series of successive solid solution featured with a pure perovskite structure have been formed and morphotropic phase boundary of the ceramics exists at $0.02<\mathrm{x}<0.06$. The BNBSST-100x ceramics compared with pure bismuth sodium titanate ceramic show a relatively large $\mathrm{P}_{\mathrm{r}}$ and low $\mathrm{E}_{\mathrm{C}}$ and the piezoelectric properties of the ceramics also are significantly improved, which due to the morphotropic phase boundary. The BNBSST-4 ceramic sample near the morphotropic phase boundary shows excellent electrical properties, the optimum values of $\mathrm{d}_{33}, \mathrm{k}_{\mathrm{p}}, \varepsilon_{\mathrm{r}}, \tan \delta, \mathrm{P}_{\mathrm{r}}$ and $\mathrm{E}_{\mathrm{C}}$ are, respectively $203 \mathrm{pC} / \mathrm{N}, 41,1128$ and $2.6 \%, 35.6 \mu \mathrm{C} / \mathrm{cm}^{2}$ and $3.51 \mathrm{kV} / \mathrm{mm}$, which suggests that the ceramics are very promising lead-free piezoelectric materials.

\section{ACKNOWLEDGEMENTS}

This work was supported by the National Natural Science Foundation of China (No. 51272001, 51072001, 51102073 and 61290301), the National Science Research Foundation of Education Ministry of China for Scholars Return from Overseas, the Natural Science Foundation of Education Department of Anhui Province (No. KJ2013B229).

\section{REFERENCES}

1. S. Katzir, Arch. Hist. Exact Sci., 57, 61 (2003).

2. T. Takenaka, K.- Maruyama and K. Sakata, Jpn. J. Appl. Phys., 30, 2236 (1991).

3. C.R. Zhou and X.Y. Liu, J. Mater. Sci., 43, 1016 (2008).

4. G.A. Smolenski and A.I. Aganovskaya, Sov. Phys. Solid State, 1, 1429 (1960).

5. D. Lin, D. Xiao, J. Zhu and P. Yu, J. Eur. Ceram. Soc., 26, 3247 (2006).

6. G. Fan, W. Lu, X. Wang and F. Liang, Appl. Phys. Lett., 91, 202908 (2007).

7. Y.J. Dai, J.S. Pan and X.W. Zhang, Key Eng. Mater., 336-338, 206 (2007). 